\title{
Ross River virus disease in two Dutch travellers returning from Australia, February to April 2015
}

C Reusken (c.reusken@erasmusmc.nl) ${ }^{1}$, N Cleton ${ }^{1,2}$, M Medonça Melo $^{3}$, C Visser $^{4}$, C GeurtsvanKessel ${ }^{1}$, P Bloembergen ${ }^{5}$, M Koopmans $^{1,2}$, J Schmidt-Chanasit ${ }^{6,7}$, P van Genderen $^{3}$

1. Department of Viroscience, WHO Collaborating Centre for Arbovirus and Haemorrhagic Fever Reference and Research, Erasmus MC, Rotterdam, the Netherlands

2. Centre for Infectious Disease Control, National Institute for Public Health and the Environment (RIVM), Bilthoven, the Netherlands

3. Institute for Tropical Diseases, Harbour Hospital, Rotterdam, the Netherlands

4. General practice Havelte, Havelte, the Netherlands

5. Laboratory for Medical Microbiology and Infectious diseases, Isala Clinics, Zwolle, the Netherlands

6. Bernhard Nocht Institute for Tropical Medicine, WHO Collaborating Centre for Arbovirus and Haemorrhagic Fever Reference and Research, Hamburg, Germany

7. German Centre for Infection Research (DZIF), Hamburg-Luebeck-Borstel, Hamburg, Germany

Citation style for this article:

Reusken C, Cleton N, Medonça Melo M, Visser C, Geurts van Kessel C, Bloembergen P, Koopmans M, Schmidt-Chanasit J, van Genderen P. Ross River virus disease in two Dutch travellers returning from Australia, February to April 2015. Euro Surveill. 2015;20(31):pii=21200. Available online: http://www.eurosurveillance.org/ ViewArticle.aspx?Articleld $=21200$

Article submitted on 17 July 2015 / published on 06 August 2015

We report two cases of Ross River virus (RRV) infection in Dutch travellers who visited Australia during February to April 2015. These cases coincided with the largest recorded outbreak of RRV disease in Australia since 1996. This report serves to create awareness among physicians to consider travel-related RRV disease in differential diagnosis of patients with fever, arthralgia and/or rash returning from the South Pacific area, and to promote awareness among professionals advising travellers to this region.

\section{Case presentation}

\section{Case 1}

A woman in her early 505 with a history of polymyalgia rheumatica visited the outpatient department of a hospital in Rotterdam because of persistent joint pains after travel to Australia. She had stayed in Australia from 30 January until 5 March, where she mainly stayed in the surroundings of Perth. From 7 February, she stayed in Cairns for six days. She recalled having had multiple mosquito bites during her stay in Cairns. Seven days after her return to Perth (on 20 February), she developed fever, fatigue, frontal headache, muscle aches and arthralgia of her hands, wrists, feet and ankles. In addition, she noticed an itchy papular rash on her face, neck and trunk. She was treated with prednisone by a local general practitioner for a presumed recurrence of her polymyalgia, pending the results of serological investigations. Serology for RRV was IgM positive, therefore treatment with prednisone was discontinued.

Two months after returning to the Netherlands, she still experienced debilitating arthralgia and an unsteady gait, frequently necessitating the use of a walking aid. In addition, she reported a subfebrile temperature and sweating. On physical examination, no abnormalities were seen. She had a normal body temperature of $36.9^{\circ} \mathrm{C}$ and her joints did not show any sign of arthritis. Laboratory investigation revealed an elevated erythrocyte sedimentation rate (ESR) of $32 \mathrm{~mm} / \mathrm{hr}$, a normal leukocyte count of $6.6 \times 10^{9} / \mathrm{L}$, no abnormalities in the differential morphology of the leukocytes and a C-reactive protein (CRP) level of $6 \mathrm{mg} / \mathrm{L}$ (norm: «10 mg/L). Serological testing for RRV on convalescent serum (taken 7 April) showed the presence of IgM and seroconversion for IgG antibodies specific for RRV (Table). RRV aetiology was further confirmed by comparative indirect immunofluorescence assay (IIFA) for RRV, Barmah Forest virus (BFV), chikungunya virus (CHIKV) and Sindbis virus (SINV), and virus neutralization (Table). BFV, CHIKV and SINV are alphaviruses causing symptoms comparable to those caused by RRV, which are endemic to the region.

\section{Case 2}

A woman in her late 6os visited her general practitioner on 11 May 2015 with complaints of fatigue, myalgia, arthralgia and a maculopapular rash but no fever. The patient had visited Australia from 29 March to 9 May 2015, where she stayed in New South Wales (in Sydney, Armidale and a mangrove forest near Coff Harbour). She recalled having been bitten by mosquitoes during a trip on 14 April. The first symptoms of wrist pains appeared around 21 April, followed by a rash a few days later. The patient visited a local physician on 27 April and treatment with meloxicam was initiated. Laboratory investigation revealed a normal erythrocyte sedimentation rate of $5 \mathrm{~mm} / \mathrm{hr}$. Diagnostics for RRV, 


\section{TABLE}

Differential diagnostics for two Dutch travellers returning from Australia with Ross River virus disease, FebruaryApril 2015

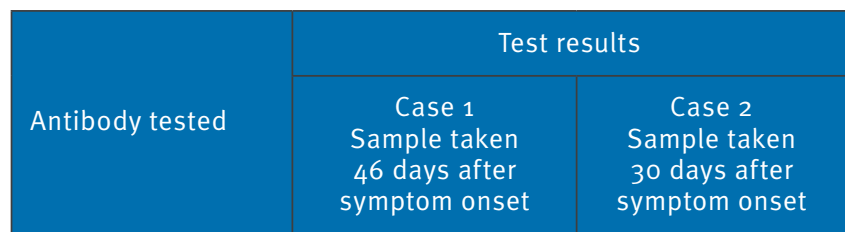

\begin{tabular}{|c|c|c|}
\hline Anti-RRV-IgGa & 2.23 & 3.64 \\
\hline Anti-RRV-IgMa & 4.81 & 6.33 \\
\hline Anti-RRV-IgG ${ }^{b}$ & $1: 10,240$ & $1: 2,560$ \\
\hline Anti-RRV-IgM ${ }^{b}$ & $1: 640$ & $1: 5,120$ \\
\hline RRV NAbc & $1: 40$ & $1: 40$ \\
\hline Anti-BFV-IgG/IgMa,b & neg & neg \\
\hline Anti-CHIKV-IgG ${ }^{b}$ & $1: 160$ & $1: 1,280$ \\
\hline Anti-CHIKV-IgM ${ }^{b}$ & $1: 320$ & neg \\
\hline CHIKV NAbc & neg & neg \\
\hline Anti-SINV-IgG/IgM b & neg & neg \\
\hline
\end{tabular}

BFV: Barmah Forest virus; CHIKV: chikungunya virus; NAb: neutralising antibodies; neg: negative; RRV: Ross River virus; SINV: Sindbis virus.

a Enzyme-linked immunosorbent assay (PanBio ELISA) values $\$ 1.0$ were considered negative.

${ }^{b}$ Indirect immunofluorescence assay titres 1 1:20 for serum were considered negative [9].

c Virus neutralisation test titres $<1: 20$ for serum were considered negative [9].

BFV, Epstein-Barr virus, B19 parvovirus and connective tissue disease were negative.

Upon the patient's return to the Netherlands, the rash reappeared (Figure) and the joint pains in her hands and knees increased. Treatment with naproxen was started. Serology for Borrelia burgdorferi showed IgM but no IgG; however, this diagnosis remained inconclusive as it was not confirmed by analysis of a second serum sample. Serological testing for RRV and BFV on a convalescent serum taken on 20 May showed the presence of IgM and IgG antibodies specific for RRV (Table). A second serum sample taken on 24 June showed decreasing IgM and increasing IgG titres. RRV aetiology was further confirmed by comparative IIFA for RRV, BFV, CHIKV and SINV, and by virus neutralisation (Table).

\section{Background}

RRV, an alphavirus transmitted by mosquitoes, is endemic in Australia and Papua New Guinea, with occasional epidemics in island countries in the Asia-Pacific region. The virus is maintained in an enzootic cycle between mosquitoes and marsupials, such as kangaroos and wallabies, as primary reservoirs. Rodents, rabbits, fruit bats, possums, horses, cats and dogs have been implicated as well [1-3]. Human-to-human

\section{FIGURE}

Rash in a traveller (Case 2) returning from Australia with Ross River virus disease, 19 May 2015, 29 days post symptom onset

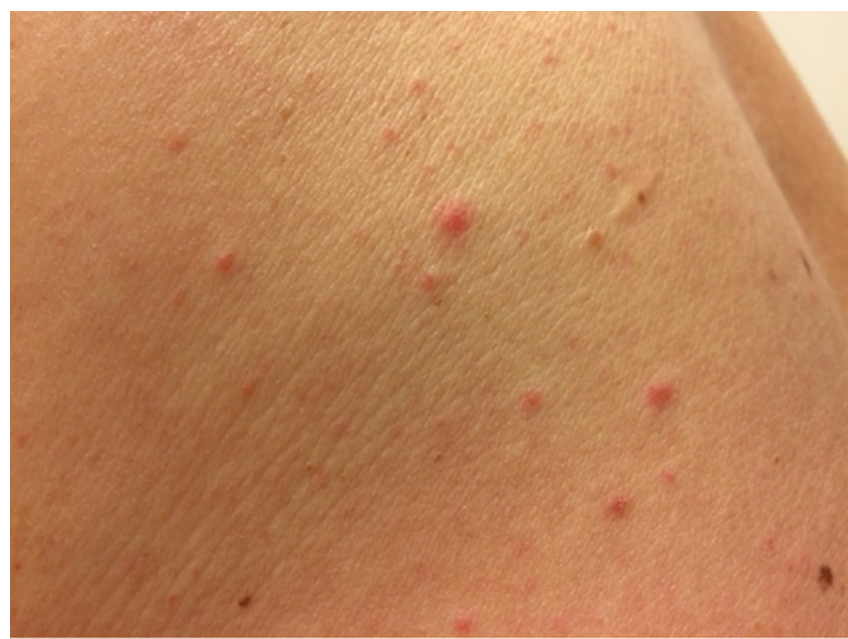

transmission has been described in epidemic situations, and viraemic travellers from Australia have been linked to epidemics in the Cook Islands, Fiji, New Caledonia and Samoa [3]. Unnoticed circulation of RRV has been described in French Polynesia [4]. Recent evidence supports RRV transmission through blood donation [5]. Mosquitoes belonging to the genera Aedes and Culex are considered the main vector species and vertical transmission has been described as a way for the virus to persist during adverse conditions in desiccation-resistant eggs [6].

RRV is endemic in tropical and subtropical Australia (Northern Territory and Queensland) with year-round notification of human cases, while in temperate Australia (New South Wales and Victoria) human cases occur seasonally and in epidemics $[3,6]$. According to the Australian Department of Health, by 23 June 2015, a total of 7,552 RRV disease cases had been reported this year, which is the largest number of annual reported cases since 1996 [7]. Most cases up to 23 June were reported in Queensland $(n=5,075)$ and New-South Wales $(n=1,292)$ and peak incidences were in February to April.

The incubation period for RRV disease (also called epidemic polyarthritis) is typically 7-9 days, ranging from 3 to 21 days [1]. In $55-75 \%$ of infections, the individuals are asymptomatic. Symptomatic disease typically includes arthralgia, myalgia and fatigue.

Low-grade fever $\left(37.5-38.5{ }^{\circ} \mathrm{C}\right)$ and maculopapular rash on the torso and limbs (sometimes palms, soles and face) occur in 50-60\% of clinical cases [1]. Joint pain, stiffness and swelling are usually symmetrical, affecting wrists, hands, fingers, ankles and knees. Additional manifestations may include headache, diarrhoea and nausea. Symptoms most often resolve 
within 3-6 months; permanent sequelae have not been described.

Treatment of symptomatic cases is supportive. Analgesics and nonsteroidal anti-inflammatory drugs may be helpful in the treatment of arthritis and arthralgia. No vaccine is available $[1,3]$.

Laboratory findings are non-specific. Leukocyte counts and CRP levels are usually normal, ESR elevated. Diagnostics are most often based on serology as the viraemic stage is very short (typically fewer than seven days post symptom onset for alphaviruses) and molecular diagnostics are not considered useful on samples taken more than a week after symptom onset. Serology is complicated by putative cross-reactivity with other alphaviruses, especially CHIKV, which belongs to the same serogroup $[1,3,8]$.

\section{Discussion}

Diagnosis of RRV disease in travellers returning to Europe is very rare [8-11]. A history of mosquito bites and stay in RRV-affected areas are epidemiological parameters supportive of a confirmative diagnosis based on RRV IgM and IgG responses. Based on these criteria, only three cases of RRV disease have been confirmed between 1 January 2009 and 30 June 2015 in the Netherlands, including the two cases in 2015 reported here, who had additional confirmation by gold-standard serology (virus neutralisation). In this period, a total of 56 diagnostic requests for RRV were submitted to the Dutch national arbovirus reference centre in Rotterdam. Of these, 20 requests indicated the travel destination as Australia and/or Asia-Pacific; for 30 requests, the travel destination was unknown. Although local circulation of RRV is unknown, travel to Indonesia, Thailand, Malaysia and the Philippines triggered diagnostic requests as well. Febrile disease and/ or arthralgia were the most common symptoms (in 21 of 35 diagnostic requests with clinical data), leading to RRV disease being considered.

The cases presented here highlight the importance of considering RRV in differential diagnosis for travellers presenting with acute arthritis returning from Australia and the Asia-Pacific region. The two cases we describe were related to travel to risk areas in Australia in February/March and March-May 2015. Other arboviruses circulating in Australia and causing polyarthritis that should be included in differential diagnosis are the alphaviruses BFV and SINV, and the flaviviruses West Nile virus (Kunjin virus, KUNV) and Kokobera virus (KOKV). Depending on other travel destinations in the Asia-Pacific region, chikungunya virus, dengue virus and Zika virus should be considered as well $[3,12]$. The annual incidence of RRV disease in Australia ranges from 2,000 to 8,000 cases; for BFV disease, from 500 to 2800 . Human cases of KUNV or KOKV disease are rare, while the occurrence of human infections with the Oceania lineage of SINV is under debate $[3,12]$.
Although RRV-viraemic travellers have been linked to the spread and epidemics with RRV in the Asia-Pacific region, it is highly unlikely that return of viraemic travellers to Europe will result in autochthonous transmission. As the duration of viraemia is short, the likelihood that a traveller will be viraemic on their return is small. More importantly, the three main vectors for RRV transmission based on field isolations and competence studies are either strictly confined to Australia (Ae. vigilax and Ae. camptorhynchus, both invasive but not established in New Zealand) or the Asia-Pacific region (C. annulirostri) [1].

This report underlines the need for awareness of RRVrelated risks among physicians, professionals advising travellers and travellers themselves. Australia is a popular travel destination for Europeans, especially for German, British and French tourists [13]. The number of leisure travellers from the Netherlands to Australia and/or New Zealand has been stable during 2002 to 2011, averaging to 52,000 travellers per year [14]. In January to March 2015, a total of 459,700 Europeans, including 12,600 from the Netherlands, had travelled to Australia [13]. Infection is preventable using common mosquito-prevention measures such as wearing long trousers, long sleeves, light-coloured clothes and insect repellents.

\section{Acknowledgements}

Tessa Bal, Sandra Scherbeijn, Sabine Köhler, Birgit Hüsing, Insa Bonow, Alexandra Bialonski, Mathis Petersen are acknowledged for excellent technical assistance. Annemiek van der Eijk for discussions and critical reading of the manuscript.

\section{Conflict of interest}

None declared.

Authors' contributions

Chantal Reusken: coordination, data analysis, wrote article. Natalie Cleton: data analysis. Mariana Medonça Melo: treating physician. Chantal Visser: treating physician. Corine Geurts van Kessel: case medical microbiologist. Peter Bloembergen: case medical microbiologist. Marion Koopmans: co-wrote article. Jonas Schmidt-Chanasit: reference testing, co-wrote article. Perry van Genderen: treating physician, co-wrote article.

\section{References}

1. Harley D, Sleigh A, Ritchie S. Ross River virus transmission, infection, and disease: a cross-disciplinary review. Clin Microbiol Rev. 2001;14(4):909-32. http://dx.doi.org/10.1128/ CMR.14.4.909-932.2001 PMID:11585790

2. Russell RC. Ross River virus: ecology and distribution. Annu Rev Entomol. 2002;47(1):1-31. http://dx.doi.org/10.1146/ annurev.ento.47.091201.145100 PMID:11729067

3. Smith DW, Speers DJ, Mackenzie JS. The viruses of Australia and the risk to tourists. Travel Med Infect Dis. 2011;9(3):113-25. http://dx.doi.org/10.1016/j.tmaid.2010.05.005 PMID:21679887

4. Aubry M, Finke J, Teissier A, Roche C, Broult J, Paulous S, et al. Silent Circulation of Ross River Virus in French Polynesia. 
Int J Infect Dis. 2015;37:19-24. http://dx.doi.org/10.1016/j. ijid.2015.06.005 PMID:26086687

5. Hoad VC, Speers DJ, Keller AJ, Dowse GK, Seed CR, Lindsay MD, et al. First reported case of transfusion-transmitted Ross River virus infection. Med J Aust. 2015;202(5):267-70. http://dx.doi. org/10.5694/mja14.01522 PMID:25758699

6. Tong S. Ross River virus disease in Australia: epidemiology, socioecology and public health response. Intern Med J. 2004;34(1-2):58-60. http://dx.doi.org/10.1111/j.14440903.2004.00520.x PMID:14748915

7. Australian Government Department of Health (DoH). National Notifiable Diseases Surveillance System. Canberra: Australian Government DoH. [Accessed 20 Jun 2015]. Available from: http://www9.health.gov.au/cda/source/rpt_4.cfm

8. Cramer JP, Kastenbauer U, Löscher T, Emmerich P, SchmidtChanasit J, Burchard GD, et al. Polyarthritis in two travellers returning from Australia. J Clin Virol. 2011;52(1):1-3. http:// dx.doi.org/10.1016/j.jcv.2011.05.008 PMID:21641275

9. Tappe D, Schmidt-Chanasit J, Ries A, Ziegler U, Müller A, Stich A. Ross River virus infection in a traveller returning from northern Australia. Med Microbiol Immunol (Berl). 2009;198(4):271-3. http://dx.doi.org/10.1007/s00430-0090122-9 PMID:19727811

10. Schleenvoigt BT, Baier M, Hagel S, Forstner C, Kötsche R, Pletz MW. Ross River virus infection in a Thuringian travelle returning from south-east Australia. Infection. 2015;43(2):22930. http://dx.doi.org/10.1007/s15010-014-0695-0 PMID:25380568

11. Visser LG, Groen J. [Arthralgia and rash from Australia caused by Ross river virus]. Ned Tijdschr Geneeskd. 2003;147(6):254-7. Dutch. PMID:12621981

12. Cleton N, Koopmans M, Reimerink J, Godeke GJ, Reusken C. Come fly with me: review of clinically important arboviruses for global travelers. J Clin Virol. 2012;55(3):191-203. http://dx.doi. org/10.1016/j.jcv.2012.07.004 PMID:22840968

13. Tourism Australia. Visitor arrivals data. Sydney: Tourism Australia. [Accessed 23 Jun 2015]. Available from: http://www. tourism.australia.com/statistics/arrivals.aspx

14. nbtc-nipo research. ContinuVakantieOnderzoek. Reisgedrag van Nederlanders 2001-2011. [Travel behaviour of Dutch travellers 2001-2011]. The Hague: nbtc-nipo research. [Accessed 29 Jun 2015]. Dutch. Available from: http://www. nbtcniporesearch.nl/nl/Home/Producten-en-diensten/cvo.htm 